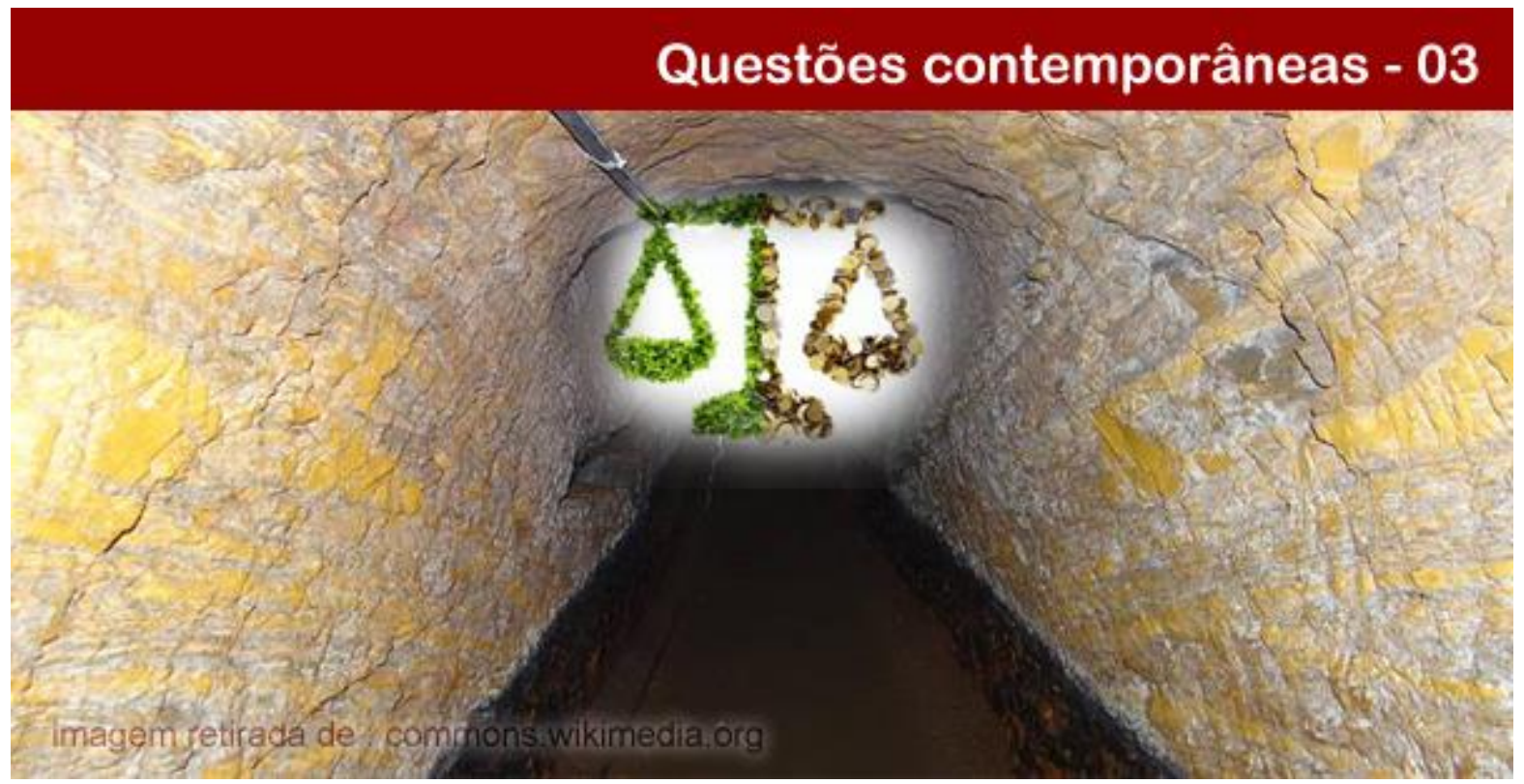

\title{
NOVO MARCO LEGAL PARA A MINERAÇÃO E SUAS IMPLICAÇÕES PARA A ATIVIDADE MINERÁRIA NO BRASIL SOB A LUZ DA JUSTIÇA AMBIENTAL
}

\section{Virgínia Maria Canônico Lopes}

Professora efetiva do Instituto Federal do Sudeste de Minas Gerais. Mestranda pelo Programa de Pós-Graduação em Extensão Rural da Universidade Federal de Viçosa - Departamento de Economia Rural (UFV/DER). Graduada em Direito pela Universidade Federal de Juiz de Fora (UFJF).E-mail: vicanonico@yahoo.com.br.

\section{Marcelo Leles Romarco de Oliveira}

Professor Adjunto IV do Departamento de Economia Rural e do Programa de Pós-Graduação em Extensão Rural da Universidade Federal de Viçosa (UFV). Doutor em Ciências Sociais pela Universidade Federal Rural do Rio de Janeiro (CPDA/UFRRJ).E-mail: mlromarco@yahoo.com.br.

Resumo: Este estudo analisou o Decreto n 9.406 de 12 de junho de 2018, para tecer um ensaio crítico sobre a abordagem legislativa acerca das normas minerárias no Brasil, após as mudanças políticas ocorridas em 2016. Neste caso, referenciado pela expectativa de um Novo Marco Legal para a Mineração no Brasil, o estudo permeia a discussão sobre a justiça ambiental, em meio ao processo político e à condução política das questões minerárias. Metodologia: foi realizada uma análise bibliográfica e documental. Documentos em arquivos oficiais, como o próprio decreto em evidência, foram tratados como fontes primárias de pesquisa. As fontes secundárias foram os estudos sobre o tema, reunidos em obras literárias. Concluiu-se que a condução política do projeto mineral no governo brasileiro, à luz da justiça ambiental, ficou relegada ao segundo plano.

Palavras-chave: Mineração. Governo. Justiça Ambiental.

\section{NEW LEGAL FRAMEWORK FOR MINING AND ITS IMPLICATIONS FOR MINING ACTIVITY IN BRAZIL UNDER THE LIGHT OF ENVIRONMENTAL JUSTICE}

\begin{abstract}
This study analyzed Decree No. 9,406 of June 12, 2018 to provide a critical essay on the legislative approach to mining standards in Brazil, following the political changes in 2016. In this case, referenced by the expectation of a New Legal Framework for Mining in Brazil, the study permeates the discussion on environmental justice in the midst of the political process and political conduct of mining issues. Methodologically, a bibliographic and documentary analysis was carried out. Documents in official archives, such as the decree itself, were treated as primary sources of research. The secondary sources were the studies on the subject collected in literary works. The political conduct of the mineral project in the Brazilian government in the light of environmental justice is relegated to the background.
\end{abstract}

\section{POLÊM!CA $\mid$ LABORE}

Polêmica - Revista Eletrônica da Uerj - Rua São Francisco Xavier, 524, $1^{\circ}$ andar bloco D, sl.1001 • Tels.: +55 21 2334-4088 / 4087 • http://www.e-publicacoes.uerj.br/index.php/polemica/index http://www.labore.uerj.br • laboreuerj@yahoo.com.br 
Keywords: Mining. Government. Environmental Justice.

\section{Introdução}

Este estudo tem como objetivo analisar como o governo do Presidente Michel Temer conduziu a política mineral brasileira, a partir de um Novo Marco Legal para a Mineração, tendo como fio condutor a publicação do Decreto n ${ }^{\circ}$ 9.406, de 12 de junho de 2018 (BRASIL, 2018a), que regulamenta o Decreto-Lei nº 227 de 1967 (atual Código da Mineração) (BRASIL, 1967), e a Lei no 13.575/17 (BRASIL, 2017b), que cria a Agência Nacional da Mineração (ANM) e extingue o Departamento Nacional de Produção Mineral (DNPM). Neste caso, o objeto empírico são as normas em relação ao setor mineral, mais precisamente o decreto referido anteriormente, que foi estudado à luz da justiça ambiental, sendo esta um contraponto ao termo injustiça ambiental, que designa o fenômeno de imposição desproporcional dos riscos ambientais às populações menos dotadas de recursos financeiros, políticos e informacionais (ACSERALD, MELLO, BEZERRA, 2009).

Tendo em vista que a grande quantidade de normas direcionadas ao setor mineral brasileiro e a elaboração do Novo Marco Regulatório da Mineração (NMM) apresentado ao Congresso Nacional, em 2013, através do Projeto de Lei (PL) $\mathrm{n}^{\circ}$ 5.807/13, de autoria do deputado Leonardo Quintão (PMDB-MG) ${ }^{1}$, são considerados pelo governo como algo necessário para o crescimento do país, é importante analisar a conduta governamental sobre estas normas e qual o viés das tratativas legislativas neste sentido. Verifica-se que junto com a construção de grandes empreendimentos, como os de geração de energia e de mineração, transformações econômicas, sociais, culturais e ambientais impactam os territórios e as comunidades atingidas.

Nas palavras de Henri Acserald, Cecília Campello do A. Mello e Gustavo das Neves Bezerra, justiça ambiental é o "direito a um meio ambiente seguro, sadio e produtivo para todos" (2009, p. 16), bem como "o direito de todo trabalhador a um meio ambiente de trabalho sadio e seguro" e "também o direito dos moradores de estarem livres, em suas casas, dos perigos ambientais provenientes das ações físico-químicas das atividades produtivas.” (2009, p. 17).

\footnotetext{
${ }^{1}$ O deputado federal Leonardo Quintão (Partido do Movimento Democrático Brasileiro - Minas Gerais) recebeu uma vultosa quantia como doação de campanha eleitoral de empresas mineradoras, nas eleições de 2014, segundo reportagem do jornal Valor Econômico. Como o deputado, foi relator do Projeto de Lei do Novo Marco Regulador do setor mineral, portanto, é razoável pensar que ele representasse estas empresas e seus interesses. O valor recebido por Leonardo Quintão corresponde a R\$ 1.030,00 milhão, segundo o Tribunal Superior Eleitoral (TSE), referente à segunda prestação de contas parcial com valores declarados até 02 de setembro de 2014.
}

\section{POLÊM!CA $\mid$ LABORE}

Polêmica - Revista Eletrônica da Uerj - Rua São Francisco Xavier, 524, $1^{\circ}$ andar bloco D, sl.1001 • Tels.: +55 21 2334-4088 / 4087 • http://www.e-publicacoes.uerj.br/index.php/polemica/index http://www.labore.uerj.br • laboreuerj@yahoo.com.br 
Neste sentido, a trajetória da mineração no território brasileiro pode estar atrelada à discussão de justiça ambiental, pois por um lado a exploração de tais recursos pode até trazer crescimento econômico ao país e, por consequência, seu desenvolvimento, mas, por outro lado, traz o empobrecimento das populações atingidas por estas obras, muitas vezes, pela perda ou destruição de seus territórios e, consequentemente, pela desarticulação dos meios de vida dessas populações impactadas por tais empreendimentos.

Desta forma, o presente estudo tem como objetivo analisar o Decreto $n^{\circ}$ 9.406/18 (BRASIL, 2018a), que regulamenta o Decreto-Lei no 227 de 1967 (atual Código da Mineração) (BRASIL, 1967) e imprime mudanças na condução da política mineral brasileira à luz da justiça ambiental. Para realizar esta tarefa, o texto apresenta, primeiramente, uma breve discussão sobre o cenário mineral brasileiro. Depois, são descritos alguns dados sobre o Decreto $\mathrm{n}^{\mathrm{o}}$ 9.406/18 (BRASIL, 2018a) em relação aos aspectos econômicos e políticos, para, por fim, trazer algumas considerações sobre a justiça ambiental envolta na confecção das normas para o setor mineral brasileiro, no governo Temer.

Como aporte metodológico foi realizado um levantamento de informações junto ao Poder Executivo e Legislativo, mais especificamente, nos sites da Presidência da República e Câmara dos Deputados, para análise documental do Decreto n 9.406/18 (BRASIL, 2018a) e do PL 5.807/13 (BRASIL, 2013). Também foi realizada a análise documental do Plano Nacional da Mineração (PNM) publicado pelo Ministério de Minas e Energia - MME (BRASIL, 2011). Por conseguinte, foi feita uma revisão bibliográfica sobre os temas à luz da justiça ambiental, buscando autores que são referência nesta temática, como Acserald (2009), Herculano (2004), Pádua (2004), Malerba et al (2012), Leroy (2011) e Alier (2017).

\section{O cenário mineral brasileiro}

As tratativas e negociações sobre uma mudança no cenário mineral brasileiro são consolidadas no estudo parlamentar do Ministério de Minas e Energia (MME), intitulado Plano Nacional de Mineração 2030 (PNM) - Geologia, Mineração e Transformação Mineral, concluído no ano de 2011. O Plano Nacional de Mineração 2030 apresenta a formulação de políticas a serem desenvolvidas pelo MME, a fim de promoverem a gestão dos recursos públicos em matéria mineral e energética para os próximos vinte anos, visando à governança pública eficaz, à agregação de valor e ao adensamento do conhecimento por todas as etapas do setor mineral e sustentabilidade. Visível está, na leitura dos objetivos do PNM, que a produção

\section{POLÊM!CA $\mid$ LABORE}

Polêmica - Revista Eletrônica da Uerj - Rua São Francisco Xavier, 524, $1^{\circ}$ andar bloco D, sl.1001 • Tels.: +55 21 2334-4088 / 4087 • http://www.e-publicacoes.uerj.br/index.php/polemica/index http://www.labore.uerj.br • laboreuerj@yahoo.com.br 
e competitividade no mercado mundial do setor mineral, com vistas ao desenvolvimento econômico capitalista, é a prioridade do governo e seu ponto de maior interesse.

Assim, de acordo com dados do PNM:

\begin{abstract}
O setor mineral - que compreende as etapas de geologia, mineração e transformação mineral - é a base para diversas cadeias produtivas. O documento destaca que o setor contribui com $4,2 \%$ do PIB e $20 \%$ do total das exportações brasileiras, gerando um milhão de empregos diretos, o equivalente a $8 \%$ dos empregos da indústria. O País destaca-se internacionalmente como produtor de nióbio, minério de ferro, bauxita, manganês e vários outros bens minerais. (BRASIL, 2011, p. 14).
\end{abstract}

E ainda, que a economia brasileira, no ano do estudo, projetava um crescimento de 5,1\% ao ano, em média, e a economia mundial, de 3,8\%. Por isso, um dos argumentos de modernizar a legislação minerária estaria na possibilidade de criar uma legislação moderna e condizente com esse cenário.

Os estímulos para construção desse plano e para alteração da legislação vigente vieram na euforia do que foi definido como boom mineral, iniciado, sobretudo, nas primeiras décadas do século XXI. No Brasil, esse boom foi classificado como o aumento significativo das cifras arrecadadas em relação à exploração de minérios, estimulando o Estado brasileiro a fomentar o setor, induzindo investimento em áreas estratégicas da economia, principalmente, nos setores de transporte e energia. Aliadas ao Estado como indutoras do desenvolvimento, as empresas privadas, nacionais e transnacionais do setor mineral, fortaleceram sua posição no território brasileiro com a concentração de capitais através da exportação de minérios.

Nesse contexto, autores como Magno (2017), apontam que o boom mineral foi um processo econômico importante para o Estado brasileiro e o PNM veio com a finalidade de “ajustar" a política à economia do setor. Para isso, o autor traz alguns dados (gráficos a seguir) que ajudam a compreender essa posição brasileira, no que diz respeito ao setor nas últimas décadas.

\title{
POLÊM!CA $\mid$ LABORE
}


Gráfico - 1: Evolução da Produção Mineral Brasileira (1975 - 2015) - Mt.

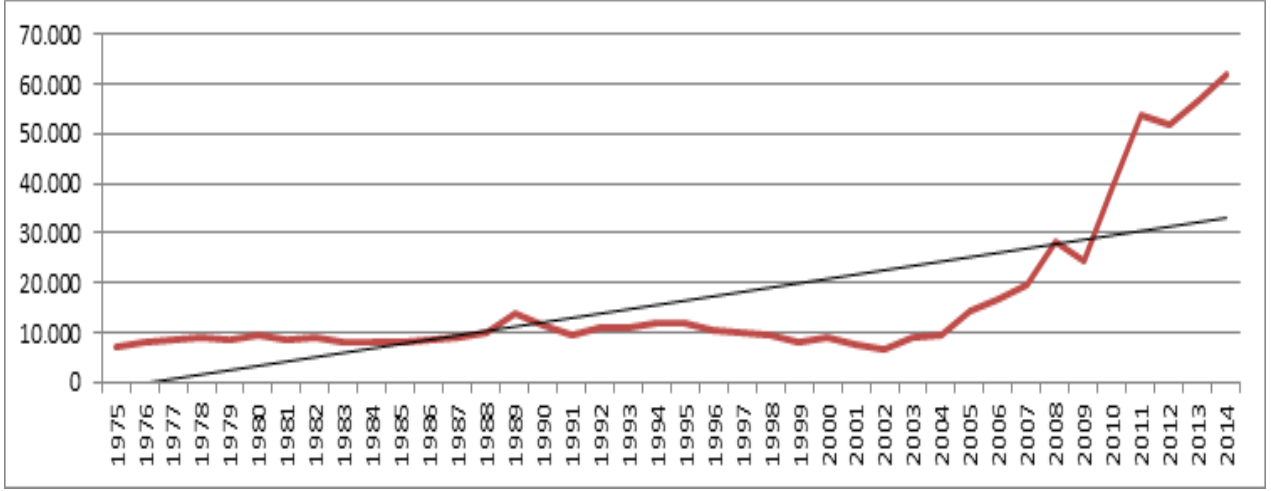

Fonte: Magno (2017, p. 165).

Gráfico - 2: Participação do setor de mineração no PIB brasileiro (em \%) entre 1980 e 2014

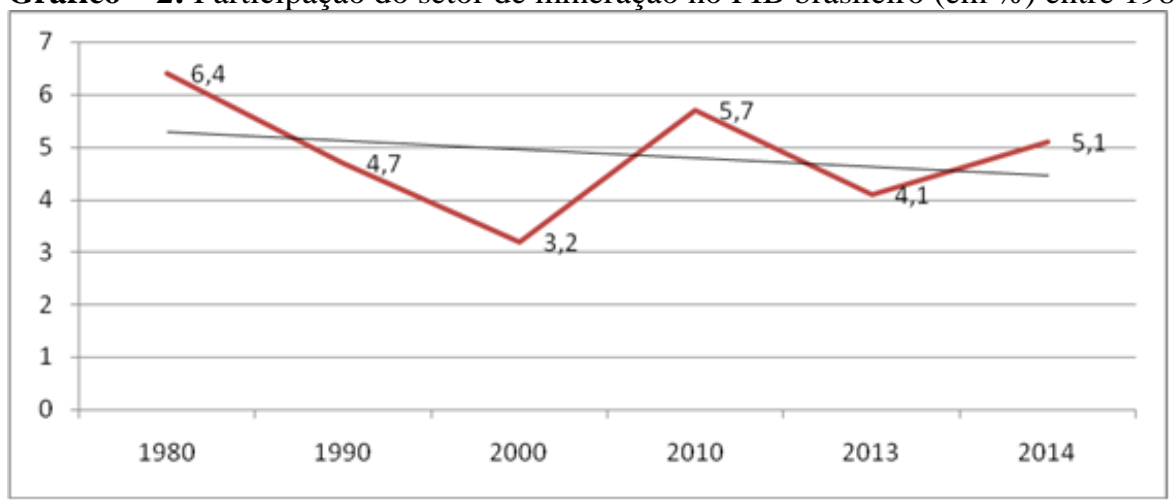

Fonte: Magno (2017, p. 167).

Gráfico - 3: Investimento no setor mineral brasileiro, 2007-2014 (em Bilhões de US\$)

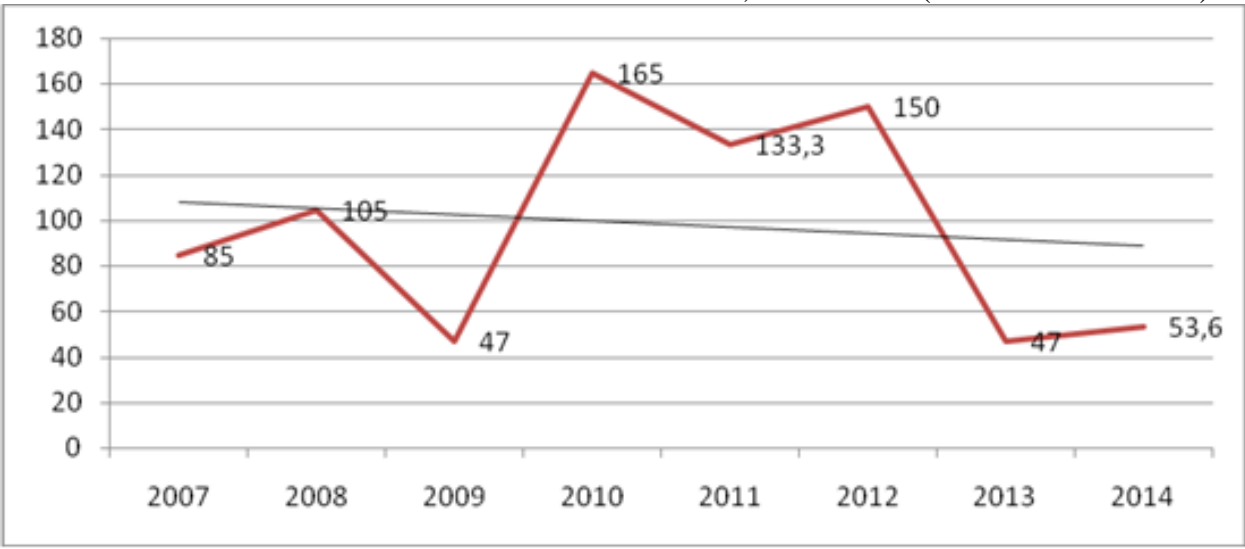

Fonte: Magno (2017, p. 170).

O gráfico 1 representa a evolução da produção mineral brasileira, entre 1975 e 2015, sendo que na última década a mineração teve grande crescimento. Segundo Magno (2017), o Brasil possui as maiores reservas de nióbio, tântalo, manganês, ferro e bauxita, minerais de grande interesse das grandes potências mundiais. A linha reta que pode ser visualizada é a linha de tendência na produção mineral brasileira, que é de aumentar. E o setor mineral tem

\section{POLÊM!CA | LABORÊ}

Polêmica - Revista Eletrônica da Uerj - Rua São Francisco Xavier, 524, $1^{\circ}$ andar bloco D, sl.1001 • Tels.: +55 21 2334-4088 / 4087 • http://www.e-publicacoes.uerj.br/index.php/polemica/index http://www.labore.uerj.br • laboreuerj@yahoo.com.br 
contribuído consideravelmente para o crescimento do Produto Interno Bruto (PIB) brasileiro, conforme mostra o gráfico 2, sendo a linha reta a linha de tendência da participação da mineração no PIB, que se mantém mais ou menos constante, com leve queda. Portanto, a ascensão do PIB brasileiro, nos primeiros anos da década de 2000, pode ser explicada no boom das commodities, em especial, do minério de ferro (MAGNO, 2017).

O gráfico 3, relativo aos investimentos na economia mineral brasileira, demonstra que foi justamente no início do século XXI que foi destinado grande volume de recursos para o setor mineral brasileiro. Neste sentido, Magno (2017) apresenta dados do Instituto Brasileiro de Mineração (IBRAM, 2015) em que investimentos na ordem de 53,6 bilhões de dólares foram feitos no setor, em 2014, e eles se encontraram basicamente nos estados de Minas Gerais e Pará, estados que, historicamente, têm valorizado a atividade de mineração para alavancar um modelo de desenvolvimento econômico. A linha reta, no Gráfico 3, representa a linha de tendência sobre os investimentos no setor mineral, que se mantém mais ou menos constante, com leve queda.

A elaboração dos gráficos apresentados acima segue a análise dos sumários minerais que são publicações do antigo Departamento Nacional de Produção Mineral (DNPM) e atual Agência Nacional da Mineração (ANM), analisados até o período de 2014.

Em complementariedade a este momento de boom mineral e a emergência de novas propostas para o setor mineral, entra em cena uma proposta legislativa com o Projeto de Lei 5.807/13 (BRASIL, 2013), a fim de atualizar o Código da Mineração em vigor e promover as mudanças socioeconômicas no Estado brasileiro que o governo espera para o setor mineral.

Esta proposta é demarcada no cenário político como o Novo Marco Regulatório para a Mineração e traz novas regras para a mineração em relação a fatores estratégicos para a atuação do governo e sua relação com as grandes empresas mineradoras, quais sejam:

- apresentar normas processuais diferenciadas para a obtenção da licença de lavra;

- implementar a transformação do Departamento Nacional de Produção Mineral (DNPM) na Agência Nacional de Mineração e;

- estabelecer uma nova fórmula de cálculo e cobrança dos royalties da exploração mineral, a denominada Compensação Financeira pela exploração de Recursos Minerais - CFEM.

Nesse período do chamado boom mineral, estávamos, no Brasil, sob o governo do Partido dos Trabalhadores, com as presidências de Luiz Inácio Lula da Silva e Dilma Rousseff

\section{POLÊM!CA $\mid$ LABORE}

Polêmica - Revista Eletrônica da Uerj - Rua São Francisco Xavier, 524, $1^{\circ}$ andar bloco D, sl.1001 • Tels.: +55 21 2334-4088 / 4087 • http://www.e-publicacoes.uerj.br/index.php/polemica/index http://www.labore.uerj.br • laboreuerj@yahoo.com.br 
(2003 a $2016^{2}$ ), sucessivamente. Os governos Lula e Dilma se aproximaram do que autores como Gudynas (2012) classificam como neoextrativismo, ou no caso dos governos de esquerda, de um neoextrativismo progressista ${ }^{3}$. Esse modelo utilizado por Gudynas nos ajuda a entender que o neoextrativismo consistiria em fomentar os investimentos em atividades que removem grande volume de recursos naturais, seja por meio da mineração ou da agricultura de monocultura, como é o caso do Brasil, com intuito de arrecadação de impostos para direcionar investimentos em programas sociais, com parte da renda destas atividades. Entretanto, essa perspectiva deixa de fora o debate dos impactos provocados por essas atividades, sobretudo, no que diz respeito às populações atingidas e impactadas por tais empreendimentos (MILANEZ, COELHO, WANDERLEY, 2017).

Como aludido acima, neste momento de boom no setor mineral, surge a proposta de um Novo Marco Regulatório Minerário com o PL 5.807/13 (BRASIL, 2013), que procura redirecionar a forma de exploração desses recursos. Entretanto, nesse novo PL, há alguns pontos a serem considerados, pois comprometem os direitos socioambientais e econômicos das populações atingidas pelos empreendimentos advindos das atividades minerárias. Podemos destacar: a não objetividade no texto do projeto de lei sobre os compromissos do minerador para com o meio ambiente e as comunidades afetadas, levando-se em consideração a legislação ambiental e trabalhista; a mudança na forma de cálculo da compensação financeira pela exploração de recursos minerais (CFEM); a autorização para atividades minerárias em área de Unidades de Conservação, terras indígenas e quilombolas é transferida do Poder Legislativo para a Agência Nacional da Mineração, sob a responsabilidade do Ministério de Minas e Energia. Tais medidas esvaziam o poder do Estado sobre as riquezas minerais e coloca em situação de fragilidade esses territórios e as comunidades que neles vivem.

Segundo Malerba et al (2012), a proposta de um novo marco regulatório para as atividades minerais no país, de um lado visa ampliar e intensificar a exploração mineral, respondendo ao atual momento de aumento de preços dos minérios e, de outro lado, pretende aumentar a participação do Estado nos resultados econômicos gerados pela mineração. No

\footnotetext{
${ }^{2}$ Em meados de 2016, Dilma Roussef sofreu o processo de impeachment, sendo afastada da Presidência, no mês de maio de 2016, por decisão do Senado Federal, momento em que o vice-presidente Michel Temer assumiu, interinamente. Em agosto de 2016, o processo de impeachment foi concluído com o afastamento definitivo da então presidenta Dilma Roussef da Presidência da República.

${ }^{3}$ Segundo Gudynas (2011), os governos chamados progressistas praticam estratégias extrativistas, mas não são idênticas às do passado, por isto, é necessário falar de um neoextrativismo progressista. Nestes governos, o Estado assume papéis mais ativos e, em vários casos, se alimenta de vários programas de luta contra a pobreza, mas seguem com base em estilo de alto impacto social e ambiental.
}

\section{POLÊM!CA $\mid$ LABORE}

Polêmica - Revista Eletrônica da Uerj - Rua São Francisco Xavier, 524, $1^{\circ}$ andar bloco D, sl.1001 • Tels.: +55 21 2334-4088 / 4087 • http://www.e-publicacoes.uerj.br/index.php/polemica/index http://www.labore.uerj.br • laboreuerj@yahoo.com.br 
entanto, "o Estado não tem sido capaz de alterar o peso das heranças patrimonialistas e excludentes sobre o controle dos recursos naturais e a distribuição desigual dos impactos negativos da exploração desses recursos sobre populações historicamente vulnerabilizadas" (MALERBA et al, 2012, p. 11).

Diante dessas questões colocadas para o Novo Código que não foram apresentadas para um amplo debate com a sociedade, o PL dava indício de que sua aprovação seria fácil, entretanto, em novembro de 2015, as discussões e análise sobre o Novo Marco Regulatório da Mineração foram paralisadas, quando ocorreu o maior desastre socioambiental da história brasileira, com o rompimento da barragem de Fundão, no município de Mariana - MG, da mineradora Samarco, com sede no município de Mariana - MG, controlada pela Vale S.A. e BHP Billiton. Naquele momento, o Congresso sentiu que era hora de recuar, e o projeto de lei deixou de ser uma urgência constitucional, por ora.

No entanto, com a conjuntura favorável a partir do Impeachment da presidente Dilma Rousseff, em meados do ano de 2016, uma abertura para o desdobramento do Novo Código por meio de portarias, decretos e medidas provisórias encontraram um terreno fértil, na gestão do Presidente Michel Temer. Essa fase recente da mineração é apresentada por autores como Milanez, Coelho e Wanderley (2017), como uma visão mais agressiva junto aos recursos minerais, pautada no extrativismo mineral voltado para exportação em larga escala. Essa nova guinada da exploração mineral brasileira nos permite apontar que, a partir do governo do Presidente Temer, o Estado intensificou seu posicionamento na abertura de capitais e investimentos externos, tornando-se menos sensível s questões sociais e ambientais do tema.

Para isso, o governo, publicou três medidas provisórias, a saber: 789, 790 e 791, de 26 de julho de 2017 (BRASIL, 2017c, d, e), que ficaram conhecidas como as Medidas Provisórias da Mineração, com o intuito de alterar vários pontos do Código da Mineração de 1967 e leis afins. As MP's de no 789 e 791 foram convertidas nas Leis 13.540, de 18 de dezembro de 2017 (BRASIL, 2017a), e 13.575, de 26 de dezembro de 2017 (BRASIL, 2017b), respectivamente. E para corroborar o fatiamento das normas para o setor mineral, em 12 de junho de 2018, o governo publicou o Decreto $\mathrm{n}^{\mathrm{o}} 9.406$ (BRASIL, 2018a), que regulamenta o Código da Mineração de 1967 vigente $^{4}$. Pode-se afirmar que, no governo Temer, a construção de um novo

\footnotetext{
${ }^{4}$ O Código da Mineração de 1967 seria atualizado pelo Projeto de Lei 5.807/13 que está parado na Câmara dos Deputados. O intuito inicial era o Novo Marco Regulatório da Mineração elaborado pelo Poder Legislativo, ainda no governo de Dilma Roussef.
}

\section{POLÊM!CA $\mid$ LABORE}

Polêmica - Revista Eletrônica da Uerj - Rua São Francisco Xavier, 524, $1^{\circ}$ andar bloco D, sl.1001 • Tels.: +55 21 2334-4088 / 4087 • http://www.e-publicacoes.uerj.br/index.php/polemica/index http://www.labore.uerj.br • laboreuerj@yahoo.com.br 
Código Mineral se deu por meio de instrumentos diversos, como portarias, medidas provisórias e decretos, que são menos sensíveis ao controle e pressão social.

\section{O Decreto no 9.406 de 12 de junho de 2018}

A política mineral brasileira, no governo do presidente Temer, intensificou os interesses e ganhos do setor privado produtivo e ainda do capital rentista e, para isto, não mediu esforços, no sentido de legislar, através de decretos, medidas provisórias e portarias, as modificações para o setor mineral brasileiro, esvaziando o projeto de lei de um novo marco regulatório para o setor, como fora proposto em 2013.

O Decreto 9.406/18 (BRASIL, 2018a), que regulamenta o Código da Mineração de 1967, faz parte do Programa de Revitalização da Indústria Mineral Brasileira, iniciado em julho de 2017, com a publicação das três medidas provisórias da mineração que resultaram em duas leis ordinárias para criação da Agência Nacional da Mineração e para alteração na forma de cobrança da compensação financeira pela exploração dos recursos minerais (CFEM). A medida provisória de $n^{\circ}$ 790/17 (BRASIL, 2017d), que perdeu sua vigência em novembro de 2017, porque não foi apreciada pela Câmara e pelo Senado em tempo hábil, familiariza vários de seus dispositivos com o Decreto em análise, a exemplo do art. 22 da MP 790/17, que é o mesmo art. 22 do Decreto $n^{\circ} 9.406 / 18$, que define sobre o alvará de pesquisa para mineração.

De acordo com análise realizada pela Coordenação Nacional do Movimento pela Soberania Popular na Mineração - MAM (2018), as mudanças provocadas pelo Decreto são a abertura de reservas nacionais, como a RENCA (Reserva Nacional de Cobre e Associados); a abertura de áreas de monopólio como no caso da exploração de urânio que é exclusiva da Indústria Nuclear Brasileira; diminuição do valor das multas aplicadas às mineradoras e a fiscalização de barragem de rejeitos por amostragem e celeridade nos processos de desapropriação de comunidades tradicionais e indígenas. Podemos concluir que, no governo de Michel Temer, este decreto foi editado para finalizar o processo de privatização dos bens minerais e representou uma irresponsabilidade com o povo brasileiro.

No caso da RENCA (Reserva Nacional de Cobre e Associados), a nova legislação permite que sejam autorizadas pesquisas e concessões de lavra de outras substâncias minerais, preservando da exploração privada apenas o cobre e os minérios associados a ele. Conforme o Decreto, a autorização será concedida pelo Ministro de Estado de Minas e Energia, após ouvir os órgãos governamentais interessados. Centralizar a decisão no Ministro de Estado é

\section{POLÊM!CA $\mid$ LABORE}

Polêmica - Revista Eletrônica da Uerj - Rua São Francisco Xavier, 524, $1^{\circ}$ andar

bloco D, sl.1001 • Tels.: +55 21 2334-4088 / 4087 • http://www.e-publicacoes.uerj.br/index.php/polemica/index

http://www.labore.uerj.br • laboreuerj@yahoo.com.br 
estratégia governamental para não chamar a atenção da sociedade para as questões que envolvem a RENCA e são decisões do Poder Executivo. No Decreto em análise, o presidente Michel Temer sancionou a exploração no território da RENCA, como era seu objetivo desde a publicação do Decreto ${ }^{\circ}$ 9.147, de 28 de agosto de $2017^{5}$.

O Ministério Público Federal (MPF), em notícia publicada no site Jusbrasil (MPF, 2018), considerou ser inconstitucional, novamente ${ }^{6}$, o instrumento utilizado pelo governo para possibilitar a exploração mineral na RENCA e quer evitar estas autorizações de pesquisa e exploração mineral. Por isto, de forma concreta, o MPF ajuizou ação na Justiça Federal, com o intuito de anular o art. 72 do Decreto $n^{\circ}$ 9.406/18 (BRASIL, 2018a), que libera a pesquisa e a lavra de substância mineral em áreas de reserva nacional.

Para o MPF, a mudança por decreto presidencial é inconstitucional e invade a competência legislativa do Congresso Nacional, a quem caberia, por meio de lei específica, fazer qualquer restrição ou alteração em área de conservação. Além disso, o ato de fomento da mineração em áreas de conservação precisaria ser previamente submetido às regras de consulta prévia, livre e informada aos povos indígenas e populações tradicionais interessados e diretamente atingidos pela medida, nos termos da Convenção da Organização Internacional do Trabalho-OIT $169^{7}$.

Portanto, resta claro que a política mineral conduzida pelo governo do presidente Temer trouxe inúmeros prejuízos às populações tradicionais e indígenas que sofrem os impactos das suas medidas, podendo perder as bases de reprodução socioeconômica, dado o caráter de controle e a reorganização do espaço que a dinâmica mineral impõe aos territórios. Desta feita, não está comtemplado na nova regulamentação do Código da Mineração os princípios da justiça ambiental e a preocupação com as normas de direito ambiental brasileiro.

\footnotetext{
${ }^{5}$ O Decreto $\mathrm{n}^{\circ}$ 9.147, de 28 de agosto de 2017 foi revogado pelo Decreto $\mathrm{n}^{\circ}$ 9.159, de 25 de setembro de 2017 , após várias manifestações da sociedade contra a extinção da RENCA e repúdio dos ambientalistas e comunidades atingidas.

6 A primeira tentativa do Governo Temer de "entregar o ouro" brasileiro foi na publicação do Decreto $\mathrm{n}^{\circ}$ 9.147/2017, que extinguia a Reserva Nacional de Cobre e Associados (RENCA), área com cerca de 46.500 km². Contra o decreto, o MPF ingressou com ação civil pública, com pedido de suspensão dos efeitos do decreto de extinção da RENCA. O juiz concedeu a liminar e, em 26 de setembro de 2017, o governo federal revogou o decreto, retornando a reserva ao status anterior.

${ }^{7}$ A Convenção ${ }^{\circ} 169$ da organização Internacional do Trabalho foi ratificada pelo Brasil, em 2002, e regulamenta os direitos dos povos indígenas e tribais em países independentes.
}

\section{POLÊM!CA $\mid$ LABORE}

Polêmica - Revista Eletrônica da Uerj - Rua São Francisco Xavier, 524, $1^{\circ}$ andar bloco D, sl.1001 • Tels.: +55 21 2334-4088 / 4087 • http://www.e-publicacoes.uerj.br/index.php/polemica/index http://www.labore.uerj.br • laboreuerj@yahoo.com.br 


\section{Justiça Ambiental e a política do governo Temer para o setor mineral}

Segundo Schüler, Lima e Pontes (2011), é clara a necessidade de mudança e adequação da legislação minerária brasileira ao novo cenário de Estado, promovido pela Constituição Federal de 1988. No entanto, estas mudanças dizem respeito ao que se afirma historicamente, de que o setor mineral ocupa posição de destaque no cenário econômico nacional. Desde o ciclo do ouro até a recente exploração das abundantes jazidas de minério de ferro, o setor tem fornecido matérias-primas indispensáveis, não apenas ao parque industrial interno, como também ao de outros países. A riqueza mineral brasileira é destacada pelos estudos promovidos pelo Ministério de Minas e Energia, demonstrando, segundo os gráficos apresentados acima, o crescimento da exportação de minérios. Desta maneira, para o governo, promover a melhoria no setor mineral e sua adequação ao cenário mundial de exploração de riquezas naturais é promover o aumento da arrecadação estatal, seguindo o modelo neoliberal. Nesta linha de atuação, é preciso dinamizar o pátio minerário, permitindo, cada vez mais, a exploração por empresas estrangeiras, a fim de taxas de lucros crescentes. E não se observa neste processo o incentivo a projetos sociais, com reversão de parte da arrecadação para a reforma agrária, para as comunidades indígenas, quilombolas ou camponesas.

Retomando, os estudos sobre o Novo Marco Legal da Mineração que foram promovidos, sobretudo, pelo Congresso Nacional, não corroboram a ideia de justiça ambiental para consubstanciar a necessidade de mudança do aparato legislativo da mineração. Muito que se fez foi apresentar diretrizes em relação à governança pública eficaz; agregação de valor e adensamento de conhecimento e sustentabilidade - MME (BRASIL, 2011).

Nesse contexto, podemos refletir que o pensamento político econômico brasileiro acerca das questões ambientais estaria associado a uma perspectiva modernizadora desse setor, podendo ser classificada como Modernização Ecológica, ou seja, um termo usado para designar uma série de estratégias de cunho neoliberal diante o impasse ecológico, mas que não comtempla a questão da desigualdade social. O crescimento econômico deve estar conciliado com as questões ambientais, mas é amparado à adaptação tecnológica e ao livre mercado, "como melhor instrumento para equacionar os problemas ambientais" (ACSERALD et al, 2009, p. 14), o que esvazia o debate político de questões como concentração de benefícios nas mãos de poucos, a destinação desproporcional dos riscos ambientais para os mais pobres e grupos étnicos (ACSERALD et al, 2009).

\section{POLÊM!CA $\mid$ LABORE}

Polêmica - Revista Eletrônica da Uerj - Rua São Francisco Xavier, 524, $1^{\circ}$ andar bloco D, sl.1001 • Tels.: +55 21 2334-4088 / 4087 • http://www.e-publicacoes.uerj.br/index.php/polemica/index http://www.labore.uerj.br • laboreuerj@yahoo.com.br 
Esse pensamento conduz ao entendimento de que os objetivos estratégicos e as ações do Plano Nacional da Mineração-2030 estão consubstanciados na "necessidade e relevância diante das previsões de produção, investimentos e geração de empregos durante o período de sua vigência”, segundo Ministério de Minas e Energia (BRASIL, 2011, p. 15).

Desta forma, é possível perceber que o tratamento da justiça ambiental não está comtemplado na justificativa para modificações na legislação minerária e este é um ponto crucial que deve ser avaliado e ser fazer constante nos estudos e alterações legais, pois os movimentos por justiça ambiental e lutas por justiça social debatem exatamente esta posição do mercado como mecanismo por excelência para regular as questões do meio ambiente (ACSERALD et al, 2009).

No Brasil, os estudos e a prática de experiências em justiça ambiental têm sido desenvolvidos por entidades associativas articuladas na Rede Brasileira de Justiça Ambiental, criada em 2001, que reúne representações de diferentes movimentos sociais, ONGs, pesquisadores de diferentes regiões do Brasil, além de um certo número de pesquisadores e representantes do movimento de Justiça Ambiental dos EUA. Jean Pierre Leroy (2011) cita a Declaração de princípios da Rede Brasileira de Justiça Ambiental para definir o que se pode entender por justiça e injustiça ambiental:

\footnotetext{
Entendemos por injustiça ambiental o mecanismo pelo qual sociedades desiguais, do ponto de vista econômico e social, destinam a maior carga dos danos ambientais do desenvolvimento às populações de baixa renda, aos grupos raciais discriminados, aos povos étnicos tradicionais, aos bairros operários, às populações marginalizadas e vulneráveis. Por justiça ambiental, ao contrário, designamos o conjunto de princípios e práticas que:

a - asseguram que nenhum grupo social, seja ele étnico, racial ou de classe, suporte uma parcela desproporcional das consequências ambientais negativas de operações econômicas, de decisões de políticas e de programas federais, estaduais, locais, assim como da ausência ou omissão de tais políticas; $\mathrm{b}$ - asseguram acesso justo e equitativo, direto e indireto, aos recursos ambientais do país;

c - asseguram amplo acesso às informações relevantes sobre o uso dos recursos ambientais e a destinação de rejeitos e localização de fontes de riscos ambientais, bem como processos democráticos e participativos na definição de políticas, planos, programas e projetos que lhes dizem respeito;

d - favorecem a constituição de sujeitos coletivos de direitos, movimentos sociais e organizações populares para serem protagonistas na construção de modelos alternativos de desenvolvimento, que assegurem a democratização do acesso aos recursos ambientais e a sustentabilidade do seu uso. (LEROY, 2011, p. 1) $)^{8}$.
}

\footnotetext{
${ }^{8}$ Declaração de princípios disponível em:

<http://www.justicaambiental.org.br/_justicaambiental/pagina.php?id=229>.
}

\section{POLÊM!CA $\mid$ LABORE}

Polêmica - Revista Eletrônica da Uerj - Rua São Francisco Xavier, 524, $1^{\circ}$ andar bloco D, sl.1001 • Tels.: +55 21 2334-4088 / 4087 • http://www.e-publicacoes.uerj.br/index.php/polemica/index http://www.labore.uerj.br • laboreuerj@yahoo.com.br 
A luta por justiça ambiental tem mantido a resistência do povo brasileiro em meio a tantas adversidades de seus governantes em relação ao meio ambiente e à possibilidade de vida no seu território, com a permanência da diversidade cultural e social, expressa pela quantidade de nomes com os quais se fala da população interiorana: povos indígenas, quilombolas, açorianos, caiçaras, pescadores artesanais, marisqueiras, ribeirinhos, extrativistas, seringueiros, quebradeiras de babaçu, coletores de castanha ou de caju, geraizeiros, jusanteiros, colonos, sertanejos, pequenos produtores, camponeses. A cada um deles, correspondem formas distintas de manter, manejar, cuidar da biodiversidade e dos ecossistemas.

Estes grupos dão sentido e concretude ao artigo 225 da Constituição Federal de 1988, que dispõe: "todos têm direito ao meio ambiente ecologicamente equilibrado, bem de uso comum do povo e essencial à sadia qualidade de vida, impondo-se ao Poder Público e à coletividade o dever de defendê-lo e preservá-lo para as presentes e futuras gerações” (BRASIL, 1988). Neste sentido, retomemos o ensinamento em Acserald et al (2009) de que:

\begin{abstract}
A noção de justiça ambiental implica, pois, o direito a um meio ambiente seguro, sadio, e produtivo para todos, onde o meio ambiente é considerado em sua totalidade, incluindo suas dimensões ecológicas, físicas construídas, sociais, políticas, estéticas e econômicas. Refere-se, assim, às condições em que tal direito pode ser livremente exercido, preservando, respeitando e realizando plenamente as identidades individuais e de grupo, a dignidade e a autonomia das comunidades. A noção de justiça ambiental afirma, por outro lado, o direito de todo trabalhador a um meio ambiente de trabalho sadio e seguro, sem que ele seja forçado a escolher entre uma vida sob o risco e o desemprego. Afirma também o direito dos moradores de estarem livres, em suas casas, dos perigos ambientais provenientes das ações físico-químicas das atividades produtivas (ACSERALD et al, 2009, p. 16-17).
\end{abstract}

Esta concepção de Acserald et al (2009) remete ao Ecologismo dos Pobres, do professor Martínez Alier, segundo o qual, hoje, existe uma exploração da natureza sem precedentes e que a quantidade de recursos necessários à produção contemporânea permite a ampliação do velho e atual intercâmbio entre países dotados de tecnologia para produzir e outros que se integram a eles como fornecedores de elementos naturais, como é o caso do Brasil.

Alier (2017) ressalta que o enfrentamento constante entre meio ambiente e economia leva os estudiosos à pretensão de "levar a natureza em consideração" (2017, p. 15) não apenas nos aspectos econômicos, mas com ênfase nos termos físicos e sociais. Aproximar estas questões é uma forma de não atribuir valores desiguais a questões que estão no mesmo patamar de valores, como aqueles dispostos na Constituição Federal de 1988 e que são artigos

\title{
POLÊM!CA $\mid$ LABORE
}

Polêmica - Revista Eletrônica da Uerj - Rua São Francisco Xavier, 524, $1^{\circ}$ andar bloco D, sl.1001 • Tels.: +55 21 2334-4088 / 4087 • http://www.e-publicacoes.uerj.br/index.php/polemica/index http://www.labore.uerj.br • laboreuerj@yahoo.com.br 
fundamentais sobre o meio ambiente, a justiça social, a participação democrática da sociedade civil, a função social da propriedade.

E, assim, o professor Alier impulsiona a análise sobre a desproporcionalidade dos impactos gerados pela exploração dos recursos naturais e sua motivação econômica, seja nos países desenvolvidos, seja nos países em desenvolvimento. Desta forma, a justiça ambiental deveria ser um dos pilares essenciais da formulação do Decreto $\mathrm{n}^{\circ}$ 9.406/18 (BRASIL, 2018). Mas a justiça ambiental e seus princípios não foram contemplados nos dispositivos deste Decreto, ficando à mercê os ensinamentos dos autores supracitados. Infelizmente, o Decreto, como norma fundamental para o setor minerário brasileiro, apenas reforça a expansão de atividades extrativas, no caso, os minérios, cujos custos sociais e ambientais têm gerado exclusão e miséria. E comtempla, acima de tudo, os interesses das grandes empresas mineradoras e a abertura de capital para a exploração mineral no território brasileiro.

A aprovação e a publicação do novo Decreto que regulamenta o Código da Mineração sem um amplo debate com a sociedade brasileira ocorreu em um momento em que o país tentava digerir o que aconteceu com o crime socioambiental provocado pelo rompimento, em novembro de 2015, da barragem de rejeito de minério da empresa Samarco em Mariana-MG, que deixou 19 mortos e um rastro de destruição em uma das principais bacias (rio Doce) hidrográficas do Sudeste brasileiro. Essa conduta política e estratégia da mineração, no Governo do presidente Temer, implicou um distanciamento dos setores estratégicos na luta pelos direitos das populações impactadas pela mineração, reforçando as críticas sobre a forte influência que políticos financiados pelas mineradoras têm sobre as normas que regulamentam o setor mineral.

No corpo do Decreto, as medidas são tomadas como alavancas ao crescimento econômico e tendem a configurar uma marcha para o crescimento, impulsionando a exploração mineral, sem, contudo, atentar para os direitos das minorias e discuti-los no teor da norma, pois que, em nenhum momento, o Decreto se refere às populações impactadas e a medidas de justiça ambiental que configurem direitos a estas populações, apesar de fazer menção à responsabilidade do minerador pela recuperação de áreas degradadas pela atividade minerária (art. $5^{\circ}, \S 2^{\circ}$ do Decreto) e pela imposição de sanções por infrações administrativas, como é o caso da aplicação de multas, conforme redação dos arts. 52 e 53 do Decreto.

No entanto, em relação à aplicação de multas, com o novo Decreto, o valor máximo desta penalidade às empresas mineradoras foi fixado em $\mathrm{R} \$ 3.293,90$ (três mil, duzentos e noventa e três reais e noventa centavos). Este valor é irrisório quando se trata de cifras

\section{POLÊM!CA $\mid$ LABORE}

Polêmica - Revista Eletrônica da Uerj - Rua São Francisco Xavier, 524, $1^{\circ}$ andar bloco D, sl.1001 • Tels.: +55 21 2334-4088 / 4087 • http://www.e-publicacoes.uerj.br/index.php/polemica/index http://www.labore.uerj.br • laboreuerj@yahoo.com.br 
bilionárias de arrecadação com a exploração mineral por parte das empresas, sejam nacionais ou estrangeiras. A aprovação deste valor máximo por parte do Poder Executivo é absurda e reforça a análise de que, com este Decreto, o governo quis permitir a exploração mineral a qualquer custo e não importa quem vai pagar a conta deste procedimento predatório dos recursos minerais.

Entre outras medidas aprovadas com o Decreto 9.406/18 (BRASIL, 2018), a autorização para exploração de minas e jazidas é competência da Agência Nacional da Mineração (ANM), segundo o art. 13 do Decreto e que, uma vez concedida a autorização, o titular pode requerer múltiplas prorrogações do prazo de autorização nas hipóteses de impedimento de acesso à área de pesquisa ou falta da licença ambiental pelo órgão competente (art. $21, \S 2^{\circ}$ ). Depreende-se, portanto, que o titular está amparado em todos os sentidos pela norma e que as manifestações contrárias à pesquisa não trarão prejuízos. Prejuízos terão as comunidades impactadas, pois, uma vez relegadas à injustiça ambiental, sofrerão o empobrecimento e o enfraquecimento de seus modos de vida.

Por fim, o art. 72 do Decreto ${ }^{\circ}$ 9.406/18, que libera a pesquisa e a lavra de substância mineral em áreas de reserva nacional, como a RENCA, e esvazia parte da legislação ${ }^{9}$ das Unidades de Conservação, desprotegendo territórios considerados estratégicos e invioláveis por certas atividades, pelo risco dos impactos em áreas onde o objetivo básico é preservar a natureza, seja nas unidades de proteção integral ${ }^{10}$, seja nas unidades de uso sustentável ${ }^{11}$. Com isto, tem-se uma insegurança jurídica para as comunidades impactadas pela mineração e a não proteção de seus territórios e modos de vida. Neste sentido, "os impactos causados pela mineração, associados à competição pelo uso e ocupação do solo, geram conflitos socioambientais, os quais, por vezes, são motivados pela ausência de políticas públicas, que reconheçam a pluralidade dos interesses envolvidos" (PONTES et al, 2013, p. 78).

\footnotetext{
${ }^{9}$ Lei no 9.985/2000 - Sistema Nacional de Unidades de Conservação da Natureza - SNUC. Disponível em http://www.planalto.gov.br/ccivil_03/Leis/L9985.htm.

${ }^{10}$ São áreas destinadas à realização de pesquisas científicas, podendo ser de domínio público ou privadas, e o objetivo básico é preservar a natureza e usar indiretamente os recursos naturais, a partir do estabelecimento de limites para sua utilização.

11 São áreas ocupadas ou não pelo homem, destinadas a preservar o ambiente natural existente, objetivando melhorar a qualidade de vida das populações e proporcionar o uso sustentável dos recursos naturais. Algumas delas servirão à pesquisa e à visitação para turismo ecológico, recreativo e educacional.
}

\section{POLÊM!CA $\mid$ LABORE}

Polêmica - Revista Eletrônica da Uerj - Rua São Francisco Xavier, 524, $1^{\circ}$ andar bloco D, sl.1001 • Tels.: +55 21 2334-4088 / 4087 • http://www.e-publicacoes.uerj.br/index.php/polemica/index http://www.labore.uerj.br • laboreuerj@yahoo.com.br 


\section{Considerações finais}

Ao longo do artigo, buscou-se sistematizar os principais problemas relacionados com a política mineral do Governo do presidente Temer, com a publicação recente do Decreto $\mathrm{n}^{\circ}$ 9.406, de 12 de junho de 2018 (BRASIL, 2018), que regulamenta o Código da Mineração vigente, em uma análise deste decreto à luz da justiça ambiental. Torna-se visível que o Brasil parece construir um novo modelo de crescimento e inserção internacional no que diz respeito à extração mineral. E, na fase Neoextrativista Liberal-Conservadora ${ }^{12}$ do governo Temer, o extrativismo mineral em larga escala para exportação manteve-se central e o direcionamento das políticas à luz da justiça ambiental tornou-se cada vez mais distante.

Dessa forma, entende-se que a mudança no direcionamento da política mineral brasileira inseriu-se na estratégia mais ampla do governo de fortalecer os interesses e ganhos do setor privado produtivo e, principalmente, do capital rentista, às custas das riquezas nacionais e da desestruturação dos modos de vida de milhares de famílias atingidas por empreendimentos minerários.

Neste cenário, os movimentos sociais e as populações tradicionais e indígenas foram relegados a segundo plano e não apareceram nos debates sobre os direitos aos territórios e direitos básicos de reprodução de seus modos de vida. Portanto, é necessário reverter esta situação, tornando o povo brasileiro protagonista na direção da política mineral brasileira. A condução política do projeto mineral no governo brasileiro leva a crer que a opção é o crescimento econômico com menor participação estatal e maior imposição de mercado, com privilégios.

O Novo Marco Legal para a Mineração no Brasil, de certa maneira, chegou ao seu desfecho com a publicação do Decreto n 9.406/18 (BRASIL, 2018a), após longa tramitação no Congresso Nacional iniciada em 2013, com o Projeto de Lei $n^{\circ}$ 5.807/13 (BRASIL, 2013), que não resultou efetivamente em um novo Código para a Mineração. Após o maior crime ambiental ocorrido no território brasileiro, com o rompimento da barragem de Fundão da empresa Samarco (Vale S.A. e BHP Billiton) no município de Mariana - MG, observou-se o recuo do governo, até então presidido por Dilma Roussef, em legislar ou pronunciar-se sobre normas para a mineração, ficando em stand by o projeto de lei que resultaria no Novo Marco Legal para a Mineração no Brasil.

12 Segundo Milanez et al (2017), após a entrada do Governo Temer, nota-se a tendência de redefinição da atuação do Estado, incluindo na regulação voltada direta e indiretamente para a atividade mineradora, além da manutenção dos esforços para a expansão dos setores primários-exportadores.

\section{POLÊM!CA $\mid$ LABORE}

Polêmica - Revista Eletrônica da Uerj - Rua São Francisco Xavier, 524, $1^{\circ}$ andar bloco D, sl.1001 • Tels.: +55 21 2334-4088 / 4087 • http://www.e-publicacoes.uerj.br/index.php/polemica/index http://www.labore.uerj.br • laboreuerj@yahoo.com.br 
No entanto, com o impeachment de Dilma Roussef e estando o país sob a presidência de Michel Temer, o tema da mineração voltou a ser analisado pelos congressistas e várias medidas foram trazidas para a pauta do Congresso Nacional, repercutindo na formulação e publicação de três medidas provisórias, conhecidas como "as medidas provisórias da mineração" (Programa de Revitalização da Indústria Mineral Brasileira), no ano de 2017, em contrapartida ao desmantelamento de várias políticas públicas. O Projeto de Lei no 5.807/13 (BRASIL, 2013) foi fatiado e não houve mais apreciação do mesmo pelo Congresso Nacional.

Das três medidas provisórias, duas foram aprovadas pelo Congresso Nacional e sancionadas pelo Presidente.

Em 18 de dezembro de 2017, foi sancionada a Lei $n^{\circ}$ 13.540, que altera a legislação de regência da Compensação Financeira pela Exploração Mineral (CFEM), que corresponde aos royalties da mineração.

No dia 27 de dezembro de 2017, Michel Temer sancionou a Lei ${ }^{\circ} 13.575$, que cria a Agência Nacional de Mineração (ANM), órgão vinculado ao Ministério de Minas e Energia (MME). Com a medida, a ANM assume as funções anteriormente exercidas pelo Departamento Nacional de Produção Mineral (DNPM), absorvendo as atividades já desempenhadas pelo órgão e exercendo novas atribuições.

Todo o aparato legislativo do governo Temer promulgado para revitalizar o setor mineral não levou em consideração o contexto político social da nossa sociedade e não comtemplaram um debate com os movimentos sociais e os atingidos, seguindo apenas o anseio desenvolvimentista do governo brasileiro.

Desta forma, a análise sobre o Decreto $\mathrm{n}^{\circ}$ 9.406/18 (BRASIL, 2018a) fez sentido para demonstrar que os avanços e os retrocessos destas políticas, no contexto econômico, social e ambiental não abordam com sistematicidade os princípios de justiça ambiental.

Portanto, resta claro que as determinações de justiça ambiental não estão interagindo com a proposta de reordenamento das regras e funcionamento do setor mineral, tão estratégico para a economia e a política de um país, ficando relegadas a segundo plano.

\section{Referências}

ACSERALD, H.; HERCULANO, S.; PÁDUA, José Augusto (orgs). Justiça Ambiental e Cidadania. Rio de Janeiro: Relume Dumará: Fundação Ford, 2004. Trabalhos apresentados no Colóquio Internacional sobre Justiça Ambiental, Trabalho e Cidadania realizado na Universidade Federal Fluminense, em setembro de 2001. ISBN 85-7316-353-4.

\section{POLÊM!CA $\mid$ LABORE}

Polêmica - Revista Eletrônica da Uerj - Rua São Francisco Xavier, 524, $1^{\circ}$ andar bloco D, sl.1001 • Tels.: +55 21 2334-4088 / 4087 • http://www.e-publicacoes.uerj.br/index.php/polemica/index http://www.labore.uerj.br • laboreuerj@yahoo.com.br 
ACSElRAD, H.; MELlO, C. C. A.; BEZERRA, G. N. O que é Justiça Ambiental. Rio de Janeiro: Garamond, 2009.

BRASIL. Câmara dos Deputados. Disponível em: <http://www.2camara.leg.br>. Acesso em: 02 jul. 2018 b.

Constituição da República Federativa do Brasil de 1988. Brasília, DF: Presidência da República, 1988. Disponível em: <http://www.planalto.gov.br/ccivil_03/Constituicao/Constituiçao.htm>. Acesso em: 28 jun. 2018.

Congresso Nacional. Projeto de Lei 5.807 de 2013. Dispõe sobre a atividade de mineração, criação do Conselho Nacional de Política Mineral e a Agência Nacional de Mineração - ANM e dá outras providências. Brasília, 2013. Disponível em: <http://www.camara.gov.br/proposicoesWeb/prop_mostrarintegra;jsessionid=34E76E6440E5A29D65F843EAD 4EC33C3.proposicoesWebExterno1? codteor=1101841\&filename=PL+5807/2013>. Acesso em: 25 jun. 2018.

Congresso Nacional. Substitutivo ao Projeto de Lei 5.807 de 2013. Dispõe sobre a atividade de mineração, criação do Conselho Nacional de Política Mineral e a Agência Nacional de Mineração - ANM e dá outras providências. Brasília, 2013.

Decreto $n^{\circ} 9.406$ de 12 de junho de 2018. Regulamenta o Decreto-Lei $n^{\circ} 227$, de 28 de fevereiro de 1967, a Lei $n^{\circ} 6.567$, de 24 de setembro de 1978, a Lei $n^{\circ} 7.805$, de 18 de julho de 1989 , e a Lei $\mathrm{n}^{\circ} 13.575$, de 26 de dezembro de 2017. Brasília, DF, 2018a. Disponível em: <http://www.planalto.gov.br/ccivil_03/_ato20152018/2018/decreto/D9406.htm>. Acesso em: 13 jun. 2018.

Decreto no 5.051 de 19 de abril de 2004. Promulga a Convenção no 169 da Organização Internacional do Trabalho - OIT sobre Povos Indígenas e Tribais. Brasília, DF, 2004. Disponível em: <http://www.planalto.gov.br/ccivil_03/_ato2004-2006/2004/decreto/d5051.htm>. Acesso em: 03 jul. 2018.

Decreto-Lei no 227 de 28 de fevereiro de 1967. Dá nova redação ao Decreto-Lei no 1.985 , de 29 de janeiro de 1940. (Código de Minas). Brasília, DF, 1967. Disponível em: <http://www.planalto.gov.br/ccivil_03/Decreto-Lei/Del0227.htm>. Acesso em: 28 jun. 2018.

Lei 13.540 de 18 de dezembro de 2017. Altera as Leis $\mathrm{n}^{\text {os }} 7.990$, de 28 de dezembro de 1989, e 8.001, de 13 de março de 1990, para dispor sobre a Compensação Financeira pela Exploração de Recursos Minerais (CFEM). Brasília, DF, 2017a. Disponível em: <http://www.planalto.gov.br/ccivil_03/_Ato20152018/2017/Lei/L13540.htm>. Acesso em: 12 jun. 2018.

Lei 13.575 de 26 de dezembro de 2017. Cria a Agência Nacional de Mineração (ANM); extingue o Departamento Nacional de Produção Mineral (DNPM); altera as Leis noㅗ 11.046, de 27 de dezembro de 2004, e 10.826, de 22 de dezembro de 2003; e revoga a Lei no 8.876, de 2 de maio de 1994, e dispositivos do DecretoLei no 227, de 28 de fevereiro de 1967 (Código de Mineração). Brasília, DF, 2017b. Disponível em http://www.planalto.gov.br/ccivil_03/_Ato2015-2018/2017/Lei/L13575.htm. Acesso em: 12 jun. 2018.

Medida Provisória no 789 de 25 de julho de 2017. Altera a Lei n ${ }^{\circ}$ 7.990, de 28 de dezembro de 1989, e a Lei $n^{\circ} 8.001$, de 13 de março de 1990, para dispor sobre a Compensação Financeira pela Exploração de Recursos Minerais. Brasília, DF, 2017c. Disponível em: <http://www.planalto.gov.br/ccivil_03/_Ato20152018/2017/Mpv/mpv789.htm>. Acesso em: 12 jun. 2018.

Medida Provisória no 790 de 25 de julho de 2017. Altera o Decreto-Lei $n^{\circ} 227$, de 28 de fevereiro de 1967 - Código de Mineração, e a Lei n ${ }^{\circ}$ 6.567, de 24 de setembro de 1978, que dispõe sobre regime especial para exploração e aproveitamento das substâncias minerais que especifica e dá outras providências. Brasília, DF, 2017d. Disponível em: <http://www.planalto.gov.br/ccivil_03/_Ato2015-2018/2017/Mpv/mpv790.htm>. Acesso em: 12 jun. 2018.

Medida Provisória no 791 de 25 de julho de 2017. Cria a Agência Nacional de Mineração e extingue o Departamento Nacional de Produção Mineral. Brasília, DF, 2017e. Disponível em: <http://www.planalto.gov.br/ccivil_03/_Ato2015-2018/2017/Mpv/mpv791.htm>. Acesso em: 12 jun. 2018.

\section{POLÊM!CA $\mid$ LABORE}

Polêmica - Revista Eletrônica da Uerj - Rua São Francisco Xavier, 524, $1^{\circ}$ andar bloco D, sl.1001 • Tels.: +55 21 2334-4088 / 4087 • http://www.e-publicacoes.uerj.br/index.php/polemica/index http://www.labore.uerj.br • laboreuerj@yahoo.com.br 
Ministério de Minas e Energia. Plano Nacional da Mineração - 2030. Brasília, 2011. Disponível em: <http://www.mme.gov.br/documents/1138775/1732821/Book_PNM_2030_2.pdf/f7cc76c1-2d3b-4490-9d45d725801c3522>. Acesso em: 27 jun. 2018.

CUNTO, Raphael Di. Mineradoras doam mais à disputa pela Câmara. Valor Econômico, São Paulo, 17 de set. 2014. A8, Política.

IBRAM - Instituto Brasileiro de Mineração. Informações sobre a economia mineral brasileira 2015. Brasília, 2015. Disponível em: <http://www.ibram.org.br/sites/1300/1382/00005836.pdf.>. Acesso em: 25 jun. 2018.

GUDYNAS, Eduardo. El Nuevo Extractivismo Progresista en America del Sur. Tesis sobre un viejo problema pajo nuevas expresiones. In: Colonialismos del Siglo XXI. Negocios extractivos y defensa del território en América Latina. Varios Autores. Icaria Editorial, Barcelona (España), junio 2011, p. 75-92.

O novo extrativismo progressista na América do Sul: teses sobre um velho problema sob novas expressões. In: LÉNA, Philippe; NASCIMENTO, Elimar Pinheiro do (orgs.). Enfrentando os limites do crescimento. Sustentabilidade, decrescimento e prosperidade. Rio de Janeiro: Garamond e IRD, 2012. p. 303-318.

LEROY, Jean Pierre. Justiça Ambiental. 2011. Disponível em: <http://conflitosambientaismg.lcc.ufmg.br/wpcontent/uploads/2014/04/TAMC-LEROY_JeanPierre_-_Justi\%C3\%A7a_Ambiental.pdf>. Acesso em: 25 jun. 2018.

MAGNO, Lucas. Espacialidade e identidade Política dos Atingidos por Mineração no Brasil: Teorias, Escalas e Estratégias. 2017. 382 p. Tese (Doutorado em Geografia) - Universidade Federal de Santa Catarina. Centro de Filosofia e Ciências Humanas. Florianópolis (SC), 2017.

MALERBA, Julianna (org.); MILANEZ, Bruno; WANDERLEY, Luiz Jardim. Novo Marco Legal da Mineração no Brasil: Para quê? Para quem? 1. ed. Rio de Janeiro: Federação de órgãos para Assistência Social e Educacional (Fase), 2012. Disponível em:

<https://fase.org.br/wpcontent/uploads/2012/09/Novo+Marco+Legal+da+Mineracao+no+Brasil+-+FASE.pdf>. Acesso em: 10 jun. 2018.

MAM - MOVIMENTO PELA SOBERANIA POPULAR NA MINERAÇÃO. Disponível em: http://mamnacional.org.br/. Acesso em: 04 jul. 2018.

MARTINEZ-ALIER, Joan. O ecologismo dos pobres: conflitos ambientais e linguagens de valoração. Tradução de Maurício Waldman. 2. ed. São Paulo: Contexto, 2017.

MILANEZ, B.; COELHO, T.P.; WANDERLEY, L. J. M. O projeto mineral no Governo Temer: menos Estado, mais mercado. Versos - Textos para Discussão PoEMAS, v. 1, n. 2, p. 1-15, 2017. Disponível em: <https://www.researchgate.net/publication/317777433_O_projeto_mineral_no_Governo_Temer_menos_Estado_ mais_mercado>. Acesso em: 11 jul. 2018.

MPF - MINISTÉRIO PÚBLICO FEDERAL. MPF quer anulação de parte do Decreto que permite exploração mineral em reservas nacionais. Jusbrasil. 2018. Disponível em:

https://mpf.jusbrasil.com.br/noticias/589611689/mpf-quer-anulacao-de-parte-do-decreto-que-permiteexploracao-mineral-em-reservas-nacionais?ref=topic_feed. Acesso em: 03 jul. 2018.

PONTES, Julio Cesar de; FARIAS, Maria S. Sobral de; LIMA, Vera Lúcia Antunes de. Mineração e seus Reflexos Socioambientais: Estudo de Impactos de Vizinhança (EIV) Causados pelo Desmonte de Rochas com Uso de Explosivos. Revista Eletrônica Polêm!ca, Rio de Janeiro, v. 12, n. 1, jan./mar. 2013, p. 77-90. Disponível em: http://www.epublicacoes.uerj.br/index.php/polemica/article/view/5277/3872. Acesso em: 05 jul. 2018.

\section{POLÊM!CA $\mid$ LABORE}

Polêmica - Revista Eletrônica da Uerj - Rua São Francisco Xavier, 524, $1^{\circ}$ andar bloco D, sl.1001 • Tels.: +55 21 2334-4088 / 4087 • http://www.e-publicacoes.uerj.br/index.php/polemica/index http://www.labore.uerj.br • laboreuerj@yahoo.com.br 
SCHÜLER, L. C.; LIMA, P. C. R.; PONTES, R. C. M. (2011): Um novo marco legal para o setor mineral. Consultoria Legislativa, Estudo. Câmara dos Deputados. Brasília, DF. 2011. Disponível em http://www2.camara.leg.br/documentosepesquisa/publicacoes/estnottec/tema16/2011_6730.pdf. Acesso em: 26 jun. 2018.

Recebido em: 11/07/2018.

Aceito em: 30/09/2018.

\section{POLÊM!CA $\mid$ LABORE}

